\section{De una Iglesia occidental a una Iglesia mundial. Una interpretación de la reforma eclesial*}

\section{Carlos Schickendantz ${ }^{* *}$}

RECIBIDO: 10-01-17. APROBADO: 25-04-17

Resumen: Según la tesis de Karl Rahner, de que el Vaticano II marcó el inicio de una Iglesia mundial, se habría concretado germinalmente un salto cualitativo que deja atrás el tiempo en el cual la Iglesia exportó su modelo cultural europeo de cristianismo. Dicha tesis puede aportar una clave para interpretar los procesos de reforma eclesial en desarrollo con el "caso Francisco". El artículo analiza tres asuntos conciliares claves que revelarían la transición de una Iglesia occidental a una Iglesia mundial: se ha frenado la "reforma de la reforma" litúrgica; en el caso de la eclesiología, ha "retornado" la categoría de pueblo de Dios; y ha llegado al obispado de Roma la recepción de Gaudium et spes más coherente con la voluntad de los padres conciliares.

Palabras clave: Vaticano II; Gaudium et spes; Ratzinger; reforma de la reforma.
From a Western Church to a World Church An Interpretation of the Ecclesial Reform

Aвstract: According to Karl Rahner's thesis that Vatican II constituted the beginning of a World Church, a qualitative leap would have taken place, by leaving behind a historical era in which the Church has exported its European cultural model of Christianity. This thesis provides a key to interpret the processes of ecclesial reform under development with the "Francis case". The article discusses three key conciliar issues that would reveal the transition from a Western Church to a World Church. The liturgical "reform of the reform" has come to an end. In the case of ecclesiology, the category God's people, has "returned". The reception of Gaudium et Spes-more coherent with the will of the Council Fathers-has reached the Church of Rome.

KeYwords: Vatican II; Gaudium et Spes; Ratzinger; Reform of the Reform.

PARA CITAR ESTE ARTÍ́CULO:

Schickendantz, Carlos. "De una Iglesia occidental a una Iglesia mundial. Una interpretación de la reforma eclesial". Theologica Xaveriana 185 (2018): 1-28. https://doi.org/10.11144/javeriana.tx68185.ioim

\footnotetext{
* Artículo de investigación que se enmarca en el proyecto del Fondo Nacional de Desarrollo Científico y Tecnológico de Chile, Fondecyt, N. ${ }^{\circ} 1150128$.

** Doctor en Teología por la Universidad de Tübingen, Alemania. Investigador del Centro Teológico Manuel Larraín, Universidad Alberto Hurtado, Santiago de Chile. OrCID: 0000-0003-3897-804X. Correo electrónico: cschickend@uahurtado.cl
} 


\section{Introducción}

La temática formulada en el título permite, naturalmente, diversos caminos para su desarrollo. Uno es la caracterización del estado actual en las reformas en las más diversas instituciones y niveles (local, regional, universal) de la vida de la Iglesia'. En el presente artículo reflexiono sobre el proceso de reforma atendiendo a lo sucedido en asuntos relevantes que, materializados en documentos centrales del Vaticano II, han tenido un desarrollo complejo, a veces contradictorio, en estas décadas, en los cuales es posible advertir una transformación importante en ejecución.

Adopto como hilo conductor la que puede considerarse como la interpretación del Concilio más citada y, probablemente, más consensuada en la comunidad científica teológica. Se trata de la "interpretación fundamental del Concilio" formulada por Karl Rahner en 1979. El autor da cuenta allí del momento histórico peculiar en el curso de la historia bimilenaria de la Iglesia que representó el Vaticano II. Refiere a que "bajo la apariencia de un desarrollo obvio y gradual, ha tenido lugar algo así como un salto cualitativo". ${ }^{2}$

La tesis que el autor aporta se formula así: “...el Concilio Vaticano II ha sido germinalmente la primera autorrealización oficial de la Iglesia en cuanto Iglesia mundial." Rahner propone una peculiar división de la historia eclesial, sin negar ulteriores subdivisiones en su interior. En principio, dicha división no tiene que ver con su extensión temporal ya que afirma que "un periodo cronológicamente breve puede esconder en sí una gran época histórica”. Desde el punto de vista teológico propone la existencia de tres grandes épocas:

- $\quad$ El primer periodo, breve, fue el del judeo-cristianismo.

- $\quad$ El segundo, el de la Iglesia existente en áreas culturales determinadas: del helenismo y de la cultura y civilización europea.

- $\quad$ El tercer periodo, que apenas ha comenzado y se ha manifestado a nivel oficial en el Vaticano II, es uno en el cual el espacio vital de la Iglesia, en principio, es todo el mundo.

Estos tres periodos estarían divididos por dos "cesuras", es decir, "el inicio de un periodo radicalmente nuevo en la historia de la Iglesia"s. La primera "introduce

\footnotetext{
${ }^{1}$ Ver a Schickendantz, "La reforma de la Iglesia en clave sinodal. Una agenda compleja y articulada". Existen tres obras colectivas destacadas recientes: Spadaro y Galli (eds.), La riforma e le riforme nella Chiesa; Baldisseri, Il Sinodo dei Vescovi al servizio di una Chiesa sinodale. A cinquant'anni dall'Apostolica solicitude; Wirz (ed.), Riformare insieme la Chiesa.

2 Rahner, "Theologische Grundinterpretation des II. Vatikanischen Konzils”, 291. Cursiva mía.

${ }^{3}$ Ibíd., 288.
} 
un cristianismo que no es exportación del cristianismo judaico en la diáspora, sino [...] un cristianismo crecido en el terreno del paganismo como tal"4. La segunda, que tiene en el Vaticano II "una especie de inicio oficial"s, representa el paso, solo inicial y poco claro, de "una Iglesia occidental a una Iglesia mundial". ${ }^{6}$

En ese marco, Rahner constata que el impulso misionero de la Iglesia en el pasado - en el segundo periodo, según su división- estuvo caracterizado, en buena medida, como una "exportación" cultural: "era un cristianismo occidental y quiso establecerse como tal, sin aventurar un nuevo inicio real interrumpiendo ciertas continuidades para nosotros obvias" de nuestra época y a las diferencias culturales de las distintas regiones la situación, se plantea de otra manera.

Las cosas están por tanto así: o la Iglesia ve y reconoce estas diferencias esenciales de las otras culturas, en el seno de las cuales debe llegar a ser Iglesia mundial, y de ese reconocimiento saca las consecuencias necesarias con audacia paulina, o bien permanece como una Iglesia occidental, a fin de cuentas, traicionando de esta manera el sentido que ha tenido el Vaticano II. ${ }^{8}$

A la luz de tal interpretación, la propuesta de esta contribución incluye dos aspectos estrechamente vinculados. Lo que ha sucedido en el plano internacional de la Iglesia con el "caso Francisco" puede ser visto como otro momento de recepción del Vaticano II. La nueva situación de la Iglesia, progresivamente a partir de marzo de 2013, tiene que ver con un nuevo impacto del Concilio, de ideas y dinamismos suyos que, por distintos motivos, fueron dejados de lado o postergados. En este nuevo escenario del debate posconciliar, hemos salido de una discusión eclesiásticopolítica de calidad teológica cuestionable acerca de la hermenéutica de la continuidad y/o de la discontinuidad, que ha marcado casi una década y ha hecho correr ríos de tinta. Además, como puede verificarse en las reflexiones que siguen, la nueva situación no solo recupera de forma más coherente el espíritu, sino incluso la letra misma de los textos conciliares que, a pesar de todas las declaraciones, la bibliografía reciente -sobre todo la romana- ha opacado en más de un caso.

Por otra parte, esta renovada recepción y diversa interpretación de la herencia conciliar pone en acto el "salto cualitativo" que describe el texto de Rahner. En el paso

\footnotetext{
${ }^{4}$ Ibíd., 294.

${ }^{5}$ Ibíd., 296.

${ }^{6}$ Ibid., 297.

${ }^{7}$ Ibíd.

${ }^{8}$ Ibid., 298.
} 
de Benedicto a Francisco podríamos estar asistiendo a la transición desde el último gran proyecto exportador del cristianismo europeo al nacimiento más decidido de una Iglesia mundial, un tipo de cristianismo objetivamente más respetuoso de las diversidades culturales y regionales. La "saludable descentralización" (Evangelii gaudium 16) representa un cauce tan natural como imprescindible en esa dinámica. Los historiadores de la Iglesia del futuro podrán evaluar esta lectura con la perspectiva de la que hoy carecemos.

El presente aporte analiza tres aspectos diversos, pero conexos. En el posconcilio cada uno de ellos ha seguido un camino propio, aunque convergente por la mentalidad y sus efectos. Me refiero aquí a tres asuntos conciliares claves -enunciados a continuación- que se materializan en los documentos Sacrosanctum Concilium, Lumen gentium y Gaudium et spes. Con el pontificado de Francisco, en el caso de la liturgia, se ha frenado la llamada "reforma de la reforma"; en el caso de la eclesiología, ha "retornado" el concepto de pueblo de Dios; en lo que se refiere a la constitución pastoral, ha llegado al obispado de Roma la recepción latinoamericana que, en buena medida, representa la recepción continental más relevante y más coherente con la voluntad de los padres conciliares cristalizada en el método inductivo que otorga a ese documento un carácter único en toda la historia conciliar de la Iglesia.

Este proceso en curso permitiría augurar un futuro más promisorio para la inculturación ulterior del cristianismo en las diversas sociedades, para la reforma sinodal de la Iglesia en todas sus instituciones, para afrontar un mundo complejo con espíritu de simpatía, sensibilidad por toda forma de alteridad y por una decidida agenda concentrada en la justica y la paz, privilegiando a los pobres y el clamor de la tierra.

Por razones de espacio, privilegio el primer asunto, el litúrgico, por tres motivos: (1) poco visible para muchos, contenía uno de los objetivos más definidos teóricamente, (2) en el cual el modelo "exportador" al que alude Rahner estaba en desarrollo; (3) además, sus efectos se introducen de lleno en el pontificado de Francisco, como lo muestran algunos sucesos de 2016.

\section{Freno a la reforma de la reforma litúrgica}

La importancia de la reforma litúrgica durante la misma celebración del Vaticano II no puede subestimarse. De hecho, como primer documento, es en dicha constitución donde se formulan las finalidades del evento conciliar (Sacrosanctum Concilium 1). Varios aspectos confluyen para fundamentar esta impresión: fue el único texto preparatorio no rechazado; existió un consenso muy amplio acerca de la necesidad de la reforma; la temática trataba un asunto pastoral próximo a las preocupaciones concretas 
de los obispos; por eso mismo, más que otras cuestiones, favoreció la participación de obispos latinoamericanos, asiáticos y africanos en los debates.

La perspectiva eclesiológica en el documento final es relevante: el lugar de la iglesia local, la responsabilidad de los obispos y las competencias de las conferencias episcopales, la participación activa de los fieles en razón del bautismo, su sacerdocio común (Sacrosanctum Concilium 14), etc. ${ }^{9}$ También el acento cristológico representa una riqueza: desarrolla una perspectiva histórico-salvífica que culmina en la centralidad del misterio pascual (Sacrosanctum Concilium 1-5).

Otro aspecto destacado es la revalorización del lugar de la Palabra de Dios. Este listado -no exhaustivo- pone de relieve el enorme significado de Sacrosanctum Concilium en el desarrollo de los trabajos de la asamblea y en el fruto expresado en el texto final aprobado por una mayoría próxima a la unanimidad; de 2152 votantes habilitados, 2.147 obispos lo hicieron de forma afirmativa-, lo cual constituye un consenso abrumador.

Desde sus inicios, la implementación de la reforma litúrgica conciliar recibió una aprobación generalizada, más o menos explícita, en los distintos estratos del pueblo de Dios. Un ejemplo: en 1966, G. Diekmann, norteamericano experto en el Concilio, escribió:

Como era de esperar, todo informe que se ha publicado hasta ahora, a escala parroquial, diocesana o más amplia, ha mostrado sin excepción que una fuerte mayoría - a veces del ochenta por ciento- está a favor de los cambios principales. El cambio más popular, como se preveía, ha sido el uso de la lengua vernácula. ${ }^{10}$

La experiencia latinoamericana también se mueve en ese sentido, según la interpretación de muchos autores: "En general, la reforma litúrgica ha sido muy bien acogida en todo el continente”, afirmó el liturgista uruguayo, R. Russo, en fecha más reciente ${ }^{11}$.

\footnotetext{
${ }^{9}$ Ver a Scardilli, I nuclei ecclesiologici nella costituzione liturgica del Vaticano II.

${ }^{10}$ Diekmann, "Estados Unidos y Canadá”, 305. La rapidez con que se difundió la lengua vernacula, incluso más allá de las cautas previsiones de los padres conciliares (Sacrosanctum Concilium 54, 36) no puede explicarse sin la descentralización de la autoridad litúrgica y el argumento de la pastoralidad (el beneficio de los fieles, el fortalecimiento de la fe, la participación activa). El Concilio atribuyó a la autoridad territorial el "determinar si ha de usarse la lengua vernácula y en qué extensión" (Sacrosanctum Concilium 36,3). El derecho litúrgico pasó a ser un derecho papal en el Código de 1917; en el movimiento litúrgico y en la etapa preparatoria del Concilio "era creciente el deseo de descentralizar también la legislación de la liturgia" (Kaczynski, "Hacia la reforma litúrgica", 209). Ver a McManus, "El poder jurídico del obispo en la constitución sobre la sagrada liturgia", 36; y a Marini, A Challenging Reform. Realizing the Vision of the Liturgical Renewal.

${ }^{11}$ Russo, "Sacrosancum Concilium e riforma liturgica in America Latina: vita liturgica e questione popolare”, 241. Ver a Rau, "La reforma litúrgica en Latino-América”, 298-300.
} 
Puede advertirse también que existe un consenso amplio acerca de la importancia que ha tenido dicha reforma, aunque no siempre se advierta su profundidad medida en una perspectiva extendida en el tiempo. Ella "constituye la única reforma mayor en la Iglesia Católica postridentina tras la reforma de la disciplina eclesial entre los siglos XVI y XVII", ha afirmado recientemente el historiador M. Faggioli ${ }^{12}$. El impacto en la vida de la Iglesia también ha sido justamente destacado: la "liturgia del Vaticano II' ha cambiado la Iglesia como ninguna otra cosa proveniente del Concilio" ${ }^{13}$. Iniciada en el mismo proceso conciliar, fue también el cambio más fácilmente perceptible para los fieles cristianos ${ }^{14}$.

Es posible constatar, por otra parte, que dicho impacto no se redujo a algunas regiones de la geografía eclesial. "Según Peter Phan, la recepción del Vaticano II en Asia comenzó con la reforma litúrgica acompañado por un esfuerzo explícito de inculturación litúrgica" ${ }^{15}$. Una verificación semejante puede realizarse en otro continente:

El efecto singular más importante en África en términos populares del Concilio ha sido el cambio en los cantos, en los himnos, en la música, en el uso de los instrumentos musicales. La Iglesia africana preconciliar tenía su corazón en la posesión del armonio. La Iglesia posconciliar se gloría en el uso de tambores. ${ }^{16}$

Algunos podrán considerar esto como una superficialidad, argumenta Orobator, pero otros la perciben "como una iniciativa de inmenso valor simbólico para la identidad de la Iglesia africana" ${ }^{17}$.

La relevancia de la reforma conciliar puede evidenciarse con dos citas significativas de Pablo VI. La primera, el domingo 7 de marzo de 1965, primero de Cuaresma de ese año, cuando comenzó a celebrarse el rito revisado:

Es extraordinaria la nueva forma actual de orar, de celebrar la santa misa. Se inaugura hoy la nueva forma de la liturgia en todas las parroquias e iglesias del mundo, para todas las misas seguidas por el pueblo. Es un gran evento, que se tendrá que recordar como principio de la floreciente vida espiritual, como un nuevo compromiso que corresponde al gran diálogo entre Dios y el ser humano. ${ }^{18}$

\footnotetext{
${ }^{12}$ Faggioli, La onda larga del Vaticano II. Por un nuevo posconcilio, 63.

${ }^{13}$ Ídem, True Reform. Liturgy and Ecclesiology in Sacrosanctum Concilium, 161.

${ }^{14}$ Polanco, "Concepto teológico de recepción con vistas a su aplicación al desarrollo posterior al Concilio Vaticano I", 221, Nota 55; Bogaz y Hansen, "Sacrosanctum Concilium”, 860.

${ }^{15}$ Faggioli, Vatican II. The Battle for Meaning, 62.

${ }^{16}$ A. Hastings, citado por Faggioli, Vatican II. The Battle for Meaning, 61.

${ }_{17}$ Orobator, "'After all, Africa is largely a Nonliterate Continent'. The Reception of Vatican II in Africa”, 298.

${ }^{18}$ Pablo VI, “Omelia, I Domenica di Quaresima”.
} 
La segunda cita, años después, en mayo de 1976, de cara al desafío lefebvriano: El nuevo Ordo fue promulgado para sustituir el antiguo, después de madura deliberación, siguiendo las instancias del Concilio Vaticano II. No de otro modo nuestro santo predecesor Pío V había hecho obligatorio el Misal reformado bajo su autoridad, después del Concilio de Trento. La misma disponibilidad exigimos nosotros, con la misma autoridad suprema que viene de Jesucristo, a todas las demás reformas litúrgicas, disciplinarias, pastorales, maduradas en estos años en la aplicación de los decretos conciliares. Cualquier iniciativa que lleve a obstaculizarlas no puede arrogarse la facultad de prestar un servicio a la Iglesia: de hecho, lleva consigo graves dańos. ${ }^{19}$

\section{La posición de Ratzinger (Benedicto XVI)}

Es verdad que ya en el tiempo de la última sesión del Concilio es posible advertir un cambio de clima, no específicamente sobre la reforma litúrgica, sino más en general, incluso bien visible en algunos textos del mismo Pablo VI, por ejemplo, en la audiencia del 28 de julio de 1965. Allí critica a quienes se aprovechan del Vaticano II, con un "reformismo radical", "como si el Concilio fuese la ocasión propicia" para poner en cuestión aspectos centrales del patrimonio tradicional de la Iglesia ${ }^{20}$. Como atestiguan varios textos, J. Ratzinger experimentó -en las semanas finales del Vaticano II, incluso antes- la sensación de que estaba en marcha un desarrollo inadecuado de las reformas conciliares. $Y$ en entrevista publicada en 2016 afirma:

La liturgia comenzó a desmoronarse deslizándose en la discrecionalidad y pronto fue claro que las intenciones positivas eran empujadas en otra dirección. Desde 1965, por tanto, sentí que era mi tarea poner en claro qué cosa queríamos de verdad y qué cosa no queríamos. ${ }^{21}$

Su mirada prevalentemente negativa del proceso posconciliar es especialmente explícita en el asunto litúrgico. En 1997, el entonces cardenal Ratzinger escribió: "Estoy convencido de que la crisis eclesial en la que nos encontramos hoy depende en gran parte del hundimiento de la liturgia". A su juicio, esto se ha debido a "una ruptura en la historia de la liturgia cuyas consecuencias solo podían ser trágicas”, que tiene su hecho central en "la prohibición del Misal que se había desarrollado a lo largo de los siglos desde el tiempo de los sacramentales de la Iglesia antigua" ${ }^{22}$. En este sentido -piensa-, el "resultado" de la "reforma litúrgica, en su realización concreta [...] no ha sido una reanimación sino una devastación” ${ }^{23}$.

\footnotetext{
${ }^{19}$ Ídem, "Concistoro per la nomina di venti cardinali".

${ }^{20}$ Ídem, "Udienza generale".

${ }^{21}$ Benedetto XVI, Ultime conversazioni, 135.

${ }^{22}$ Ratzinger, Mi vida. Recuerdos (1927-1977), 122-125.

${ }^{23}$ Ídem, "Prefazione".
} 
Debe advertirse que la crítica del cardenal Ratzinger no se refería solo a los experimentos o excesos litúrgicos, como lo había hecho el Sínodo extraordinario de obispos de 1985, al conmemorar los veinte años del Vaticano II, sino a la misma "política" oficial: "la creación de un volumen del todo nuevo", es decir, en palabras explícitas, a la reforma puesta en práctica particularmente entre los años 1965 y 1975, cuando se confeccionaron los libros litúrgicos reformados (Misal, Liturgia de las horas, leccionarios, rituales de sacramentos, etc.). El problema, a su juicio, no era el Concilio -la constitución Sacrosanctum Concilium de 1963-, sino su implementación en los años posteriores. Cuando Benedicto se refiere a la "hermenéutica de la discontinuidad y de la ruptura", en el célebre discurso de 2005, tal "ruptura" debe entenderse, en el marco de la bibliografía de Ratzinger-Benedicto, ante todo, por lo acontecido en la liturgia ${ }^{24}$.

En ese contexto se comprende el motivo por el cual, con un documento de septiembre de 2007, Summorum pontificum, el ya papa Benedicto "reintrodujo" la celebración de la eucaristía con el Misal llamado de Pío V, además de todos los otros libros litúrgicos "preconciliares". El texto de 2007, de enorme envergadura, ampliaba un documento anterior de Juan Pablo II, de 1988. Desde entonces, el Misal renovado del Concilio y el anterior conviven como "dos usos del único rito romano", uno ordinario, el de Pablo VI, el otro extraordinario, el de Pío V. Benedicto XVI era consciente que con esta medida se planteaban innumerables dificultades. Algunas eran sencillas de imaginar; por ejemplo, la introducción del anterior ritual podía favorecer una desvalorización del ritual vigente.

Era previsible que muchos autores consideraran que, con esta medida, se relativizaba el Concilio ${ }^{25}$. La política restrictiva en relación con las traducciones litúrgicas, el deseo de retomar la tradición de la celebración "de espaldas" al pueblo, más exactamente "de cara" a un altar dirigido a oriente o a una imagen del Señor no concretada solo para no introducir más cambios ${ }^{26}$, la revisión de la traducción de la fórmula de la consagración eucarística, guiada por un criterio de literalidad -cambiar el "por todos" por el pro multis, "por muchos" latino- contra la voluntad explícita casi unánime de episcopados enteros, como el italiano y el alemán, constituyen otros ejemplos de una agenda bien definida por su parte, pero con escaso eco entre los mismos obispos; menos

\footnotetext{
${ }^{24}$ Schickendantz, "La reforma de la reforma litúrgica. Un diagnóstico con poco consenso del obispo emérito de Roma”, 40-43.

${ }^{25}$ Ver a Gerhards, “ Die Sorge der Päpste. Das Motu proprio Benedikts XVI. Zur Wiederzulassung der alten Liturgie".

${ }^{26}$ Ver a Ratzinger, Obras completas XI. Teología de la liturgia, xv.
} 
aún con los especialistas ${ }^{27}$. Otras iniciativas promovidas por él podrían citarse: por ejemplo, la eliminación de la comunión en la mano, en las celebraciones papales, etc. El diagnóstico de Ratzinger-Benedicto era bien claro:

....se ha desarrollado la impresión de que la liturgia se "hace", que no es algo que existe antes que nosotros, algo "dado", sino que depende de nuestras decisiones. [...]. Pero cuando la liturgia es algo que cada uno hace a partir de sí mismo, entonces no nos da ya la que es su verdadera cualidad: el encuentro con el misterio, que no es un producto nuestro, sino nuestro origen y la fuente de nuestra vida. ${ }^{28}$

En el ámbito litúrgico se expresa el error eclesiológico, núcleo del problema, según su manera de ver: la Iglesia ya no es una realidad dada, que se recibe, sino una construcción humana librada a nuestra voluntad ${ }^{29}$; un argumento repetido en su bibliografía.

Estas preocupaciones concuerdan bien con la idea explicitada por el mismo Ratzinger acerca del primado de Sacrosanctum Concilium para una hermenéutica del Concilio. A. Grillo la ha mostrado con brevedad y exactitud a partir del discurso del entonces cardenal Ratzinger sobre la eclesiología de Lumen gentium en 2000:

...Vaticano II quiso claramente insertar y subordinar el discurso sobre la Iglesia al discurso sobre Dios; quiso proponer una eclesiología en sentido propiamente teológico, pero la acogida del Concilio hasta ahora ha omitido esta característica determinante, privilegiando algunas afirmaciones eclesiológicas.

En ese marco se comprende su interpretación de la Constitución litúrgica: "Al inicio, el hecho de que fuera la primera se debió a motivos prácticos. Pero, retrospectivamente, se debe decir que, en la arquitectura del Concilio, tiene un sentido preciso: lo primero es la adoración. Y, por tanto, Dios"30.

De allí que el primado de la liturgia -entendida esta en clave de adoración- es su llave de comprensión del Concilio que redimensiona todo proyecto de reforma, y lo convierte en secundario, o lo reduce a una mera conversión interior. En esta lectura del cardenal alemán, la participación activa no aparece como la idea central

\footnotetext{
${ }^{27}$ Baldovin, Reforming the Liturgy. A Response to the Critics, 86: "La perspectiva del cardenal Ratzinger sobre la arquitectura de las iglesias y la música litúrgica muestra cuán lejos está él del consenso sobre la naturaleza de la participación activa que la mayoría de los académicos apoyaría. Esto no quiere decir, simplemente, que está equivocado [...] y que ellos tienen razón, sino solo advertir que tiene una visión muy diferente de la liturgia posconciliar".
}

${ }^{28}$ Ratzinger, Mi vida. Recuerdos (1927-1977), 125.

${ }^{29}$ Ratzinger y Messori, Informe sobre la fe, 53-54.

${ }^{30}$ Ratzinger, "Conferencia del cardenal J. Ratzinger sobre la eclesiología de la Lumen gentium”. 
de la reforma litúrgica que -como pone de relieve Grillo- es el acto reformador por excelencia (participatio activa).

Un punto es llamativo en la interpretación de Ratzinger en el texto de 2000 citado: una "tesis metatextual", argumenta Grillo-el primado de Dios en Sacrosanctum Concilium, en los términos explicados, y como idea clave para la interpretación del Concilio- aparece "casi impuesta a la letra de los textos", precisamente en un autor, Ratzinger, quien ha insistido en regresar a los textos conciliares como remedio a los abusos hermenéuticos denunciados por él mismo ${ }^{31}$.

\section{Primer paso de la reforma de la reforma: Summorum pontificum [2007)}

Es claro que, más allá de las palabras precisas, estaba en desarrollo una "reforma de la reforma litúrgica" cuyos pasos ulteriores ya no es posible imaginar luego de febrero de 2013. Es difícil evaluar hasta dónde el episcopado mundial advertía esta agenda precisa de Benedicto, no solo las decisiones aisladas, y la compartía en su totalidad. Múltiples indicaciones provenientes de distintos países sugieren que no existía un consenso sobre el asunto; pero estaba en desarrollo un proceso bien definido. Puede ofrecerse aquí un testimonio importante, entre otros posibles.

El levantamiento de las restricciones al uso del Misal romano de 1962 de Benedicto XVI, conocido como el rito tridentino, es solo el primer paso en una "reforma de la reforma" en la liturgia, expresó el cardenal Kurt Koch, presidente del Pontificio Consejo para la Promoción de la Unidad de los Cristianos, el 14 de mayo de 2011. En efecto -afirmó-, el papa está lanzando un nuevo movimiento de reforma litúrgica. Koch hizo las declaraciones en una conferencia en Roma sobre Summorum pontificum. El texto del cardenal fue publicado el mismo día por L'Osservatore romano.

Esto explica por qué Benedicto XVI introdujo un nuevo movimiento reformista, comenzando por dicho motu proprio. El objetivo - dijo Koch- es revisar las enseñanzas del Vaticano II en la liturgia y fortalecer ciertos elementos, incluyendo la dimensión cristológica y la sacrificial de la misa. El cardenal suizo afirmó que Summorum pontificum es "solo el comienzo de este nuevo movimiento litúrgico". Y declaró:

De hecho, el papa Benedicto sabe muy bien que, a largo plazo, no podemos detenernos en una coexistencia entre la forma ordinaria y la forma extraordinaria del rito romano, sino que en el futuro la Iglesia necesitará naturalmente un rito común [...]. Sin embargo, debido a que una nueva reforma litúrgica no se puede decidir teóricamente, sino que requiere un proceso de crecimiento y

${ }^{31}$ Girardi y Grillo, “Sacrosanctum Concilium. Introduzione”, 65. 
purificación, el papa subraya por el momento, sobre todo, que las dos formas del rito romano pueden y deben enriquecerse mutuamente. ${ }^{32}$

En ese contexto se comprenden afirmaciones más recientes del cardenal Robert Sarah, prefecto de la Congregación para el Culto Divino y la Disciplina de los Sacramentos, el 5 de julio de 2016, en una conferencia en Londres titulada, precisamente, "Hacia una auténtica implementación de Sacrosanctum Concilium"33. Luego de citar la expresión "reforma de la reforma", afirma que no descarta que sea posible y deseable una "reforma oficial de la reforma litúrgica", y añade:

De hecho, puedo decir que cuando fui recibido en audiencia por el santo Padre en abril pasado, el papa Francisco me pidió que estudiara la cuestión de la reforma de una reforma y el modo en que las dos formas del rito romano podrían enriquecerse mutuamente. Este será un trabajo largo y delicado y les pido su paciencia y oraciones. Pero si queremos llevar a cabo Sacrosanctum Concilium más fielmente, si queremos lograr lo que el Concilio deseaba, esta es una cuestión seria que debe estudiarse cuidadosamente y actuar con la necesaria claridad y prudencia en la oración y sumisión total a Dios. ${ }^{34}$

Además, en referencia a la orientación de la celebración eucarística, ad orientem, expresó:

Quiero hacer un llamamiento a todos los sacerdotes. Pueden haber leído $\mathrm{mi}$ artículo en L'Osservatore romano hace un año (12 de junio de 2015) o mi entrevista con la revista Famille chrétienne en mayo de este año. En ambas ocasiones dije que creo que es muy importante que volvamos, lo antes posible, a una orientación común de sacerdotes y fieles reunidos en la misma dirección hacia el este o al menos hacia el ábside, al Señor que viene, en aquellas partes de los ritos litúrgicos cuando nos dirigimos a Dios. Esta práctica está permitida por la actual legislación litúrgica. Es perfectamente legítima en el rito moderno. De hecho, creo que es un paso muy importante para asegurar que en nuestras celebraciones el Señor esté verdaderamente en el centro. Y así, queridos padres, les pido humilde y fraternalmente que pongan esto en práctica donde sea posible, con prudencia y con la catequesis necesaria, ciertamente, pero también con la confianza de un pastor de que esto es algo bueno para la Iglesia, algo bueno para nuestro pueblo. Su propio juicio pastoral determinará cómo y cuándo esto es posible, pero tal vez comience esto el primer domingo de Adviento de este año, cuando asistimos al "Señor que vendrá" y "que no tardará" (véase: Introito, miércoles de la primera semana de Adviento) puede ser un muy buen momento para hacer esto. ${ }^{35}$

\footnotetext{
${ }^{32}$ Koch, "Pope's 'Reform of the Reform' in Liturgy to Continue".

${ }^{33}$ Sarah, "Towards an Authentic Implementation of Sacrosanctum Concilium".

${ }^{34}$ Ibíd.

${ }^{35}$ Ibíd.
} 
El cardenal Sarah ya ha repetido frases semejantes, lo cual permite corroborar que, en este caso, no se exponían ideas ocasionales, carentes de reflexión previa. El 11 de julio de 2016, la Santa Sede desautorizó dichas expresiones:

No están, por lo tanto, previstas nuevas directrices litúrgicas a partir del próximo Adviento como alguno ha deducido impropiamente de algunas palabras del cardenal Sarah, y es mejor evitar utilizar la expresión "reforma de la reforma", refiriéndose a la liturgia, dado que a veces ha sido fuente de equívocos. ${ }^{36}$

El texto recuerda, además, la "Instrucción general del Misal romano", "que contiene las normas relativas a la celebración eucarística y está siempre plenamente vigente", incluida la celebración "de cara al pueblo" ${ }^{37}$. Se descartaba, además, que hubiera alguna modificación prevista en los ritos ordinario y extraordinario de la misa tal como hoy se encuentran ${ }^{38}$.

\section{Una diferencia "generacional" y de lugar hermenéutico}

¿Cómo puede explicarse e interpretarse el proceso vivido en esta última década, particularmente en el tránsito de Benedicto a Francisco? ¿Qué asuntos de fondo están en juego en el itinerario sobre la liturgia descrito? Entre otros autores que podrían citarse, el liturgista espańol Lino Díez Valladares ha advertido el problema en un doble aspecto. Por una parte, la diversidad "generacional" entre Benedicto y Francisco y, por otra, la "evidente diferencia con los criterios recientes sobre los mismos temas".

Francisco, como papa, es "el primer 'hijo' del Concilio", "el fruto de una generación sucesiva a la de J. Ratzinger, profundamente transformada, precisamente por el Vaticano II, en sus lenguajes y en sus prioridades".

[Emerge así] una diferencia de referencias eclesiales, de sensibilidad pastoral y de cultura teológica mucho más grande e incisiva de lo que se pueda pensar: una pequeña diferencia biográfica de nueve años se convierte en una auténtica diferencia "generacional". ${ }^{39}$

Es interesante advertir que dichas observaciones fueron realizadas en 2014, antes de los sucesos recién referidos con el cardenal Sarah. En relación con estos temas y textos de Evangelii gaudium, Díez Valladares afirma:

\footnotetext{
${ }^{36}$ Sala Stampa della Santa Sede, "Comunicado de la oficina de prensa de la Santa Sede".

${ }^{37}$ El número 299 afirma: "Constrúyase el altar separado de la pared, de modo que se le pueda rodear fácilmente y la celebración se pueda realizar de cara al pueblo, lo cual conviene que sea posible en todas partes. El altar, sin embargo, ocupe el lugar que sea de verdad el centro hacia el que espontáneamente converja la atención de toda la asamblea de los fieles".

${ }^{38}$ Ver a Giraudo, "La riforma liturgica a 50 anni dal Vaticano II. 'Parlare di riforma della riforma' è un errore".

${ }^{39}$ Díez Valladares, “El desafío litúrgico del papa Francisco”, 97, Nota 2.
} 
Por último, resulta muy significativa la repetida insistencia a lo largo de la exhortación a aspectos que tienen que ver con la inculturación - "la gracia supone la cultura, y el don de Dios se encarna en la cultura de quien lo recibe" (N. $\left.{ }^{\circ} 115\right)$; "no es indispensable imponer una determinada forma cultural [...] junto con la propuesta del Evangelio" (N. ${ }^{\circ} 117$ )-, la adaptación -"hay que atreverse a encontrar los nuevos signos, los nuevos símbolos, una nueva carne para la transmisión de la Palabra..." (N. $\left.{ }^{\circ} 167\right)$, o a la atención al lenguaje, el cual a fuerza de ser ortodoxo podría llegar a ser incomprensible... (cfr. N. ${ }^{\circ} 41$ ). Leyendo estos últimos textos, y vista la evidente diferencia con los criterios recientes sobre los mismos temas, cabe plantearse más de un interrogante sobre la actual situación de la renovación en curso de los libros litúrgicos (Misal y leccionarios, especialmente) en nuestra Iglesia española. ${ }^{40}$

Sin embargo, la diferencia no es solo generacional. Ha cambiado el lugar desde donde se mira: otra geografía, otra cultura, otra experiencia eclesial. Han cambiado los acentos teológicos, las prioridades pastorales y -muy importante- la misma interpretación del Concilio. El proceso posconciliar es también percibido y valorado de diferente manera. Hay otro diagnóstico y otra terapia. Desde una periferia eclesial, la latinoamericana, se reformula la interpretación y la línea de gobierno del centro romano.

Esto deja a la luz, una vez más, los efectos hermenéuticos decisivos que tiene una política de centralización. El objetivo es ahora, más claramente, la salida misionera entendida como diálogos de procesos de inculturación que exigen una renovada creatividad. Esto reclama una continua renovación de la reforma litúrgica, es verdad, pero no en el sentido en que se la orientaba. Traducir lo más fielmente-literalmenteel ritual romano no es ahora el objetivo que guía el camino ${ }^{41}$. Inculturar, no traducir, es el verbo por conjugar en el futuro. Representa, en los términos de Rahner, el inicio de una Iglesia mundial.

\footnotetext{
${ }^{40}$ Ibíd., 98.

${ }^{41}$ No obstante, creo que aun cuando el diagnóstico y los deseos personales de Ratzinger puedan no compartirse (retomar la orientación de la celebración eucarística hacia oriente, hacia el sol que despunta, con sentido escatológico y cósmico, lo cual significa de espaldas al pueblo), incluso su consideración del doble uso del único rito (con la forma extraordinaria del llamado Misal de Pío V), deben tomarse en consideración sus preocupaciones (una eucaristía como autocelebración de una comunidad que solo se mira a sí misma en lugar de acoger la obra que Dios hace en la liturgia) como advertencias saludables para concretar una inculturación que signifique, por una parte, un desarrollo orgánico como lo deseaba el Concilio (Sacrosanctum Concilium 23), y por otra, no una mera adaptación superficial y acomodaticia a determinadas modas culturales.
} 


\section{El oscurecimiento y el regreso de la categoría de pueblo de Dios}

El capítulo segundo de Lumen gentium, "De populo Dei”, representó, por varios motivos, una "revolución copernicana” en la eclesiología: “...es nuevo por su contenido, su título y su lugar, a tal punto que no tiene antecedentes en el magisterio y señala una innovación discontinua”. ${ }^{42}$ El concepto no designa, ante todo, a los fieles cristianos laicos, a diferencia de la jerarquía, "sino a la Iglesia en su totalidad"; y representa, en este sentido, "una re-volutio en el sentido originario del término" ${ }^{43}$.

La recepción del concepto en el periodo posconciliar ha estado marcada por diversas controversias que han condicionado fuertemente su comprensión. En una primera etapa, por la controversia carisma-institución, en la cual la categoría apareció como "una bandera de parte" ${ }^{44}$; emergieron reducciones sociopolíticas en la línea de una "Iglesia democrática", en autores europeos, y en clave de "Iglesia clasista", en autores latinoamericanos. ${ }^{45}$

Indudablemente, este tipo de contraposición colaboró a un movimiento de péndulo que encontró, incluso, una formulación oficial. En el Sínodo extraordinario de obispos de 1985 se destacó, con justicia, el valor de la noción de communio: la relación final afirma que la "eclesiología de comunión es una idea central y fundamental en los documentos del Concilio" (II. C 1); al mismo tiempo se opacó la importancia del concepto de "pueblo de Dios". El hecho de que dicho término aparezca en el documento final solo una vez y en un listado -como una noción más entre otras- pareció dar razón a la advertencia expresada entonces por J. Komonchak: “...no deja de ser un desenlace sorprendente en un documento que pretende llamar la atención contra las lecturas parciales y selectivas de los textos conciliares”" ${ }^{3}$.

También J.-M. Tillard llamó la atención entonces. Advertía varios "deslizamientos" o "desplazamientos de los acentos", entre ellos, precisamente, el oscurecimiento de la noción de "pueblo de Dios". Más recientemente, D. Vitali y C. Galli, en particular, han advertido con más detalle esta insuficiencia y su importancia. Después de constatar la única mención de la categoría en la Relatio finalis, "como si fuera una expresión más del misterio", el teólogo argentino afirma:

\footnotetext{
${ }^{42}$ Galli, “El 'retorno' del pueblo de Dios misionero. Un concepto-símbolo de la eclesiología del Concilio a Francisco", 410.

${ }^{43}$ Pottmeyer, "La Chiesa in cammino, per configurarsi come popolo di Dio", 75.

${ }^{44}$ Vitali, Popolo di Dio, 189.

${ }^{45}$ Galli, "El 'retorno' del pueblo de Dios misionero", 414.

${ }^{46}$ Komonchak, "El debate teológico", 384.
} 
Si el diagnóstico se centraba en la crisis de la noción, era lógico que el remedio declarara su sentido de forma coherente. Partiendo de este texto no se podía sospechar que ella fuera el título de un capítulo y una columna arquitectónica de Lumen gentium. ${ }^{47}$

Se observa en este asunto el mismo procedimiento que verificamos antes en el campo de lo litúrgico. Por una parte, el Sínodo de 1985 pide un regreso a los textos conciliares, pues se considera que un determinado espíritu y hermenéutica los ha traicionado. Por otra, se introducen interpretaciones "desde fuera" que manifiestamente cambian o devalúan lo expresamente afirmado por el Concilio.

J.-M. Tillard opina que el ocaso de este concepto colaboró a que no hubiera en el texto de 1985 ninguna referencia a la igualdad de todos los bautizados y bautizadas, a la dignidad y responsabilidad común ${ }^{48}$. Precisamente, la del pueblo de Dios "es una lógica igualitaria, que parte de la unidad de todos los bautizados, entendidos como universitas fidelium que evidencia la común dignidad antes de toda diferencia de vocaciones, estado de vida o función” ${ }^{49}$.

Estas observaciones no pretenden desvalorizar los aportes que pueden brindar un nuevo acento: la noción de comunión. Sin duda, esta categoría puede contribuir a ilustrar una visión genuinamente teológica, a integrar unidad y diversidad en la Iglesia, incluso en perspectiva ecuménica, y a afrontar algunos de los principales problemas "estructurales" planteados en el Sínodo de entonces (relación entre Iglesia universal e iglesias particulares, naturaleza teológica y lugar de las conferencias episcopales y del sínodo de obispos, etc.). No obstante, lo sucedido con el concepto de "pueblo de Dios" no puede minusvalorarse; más aún si se presta atención al desarrollo posterior de múltiples documentos magisteriales que, simplemente, ignoran la categoría ${ }^{50}$.

Por el contrario, como han mostrado algunos autores, asistimos con Francisco y Evangelii gaudium al regreso de la categoría de "pueblo de Dios" detenernos un poco en esta forma de entender la Iglesia”, expresa en el número 111 y menciona 21 veces el concepto en el documento, notablemente más que cualquier otra noción eclesiológica. Destaca con ella el "carácter histórico" del "misterio" de la Iglesia, por una parte, y, por otra, la "inclusión de todos los bautizados", con

${ }^{47}$ Galli, “El 'retorno' del pueblo de Dios misionero”, 413.

${ }^{48}$ Tillard, "El 'Informe final' del último Sínodo", 393-407; Vitali, Popolo di Dio, 8, 153-191.

${ }^{49}$ Ibíd., 190. Ver a Vitali, "I soggetti della sinodalità alla luce dell'ecclesiologia del Concilio Vaticano II", 155-158.

${ }^{50}$ Gallí cita como ejemplos las encíclicas Ecclesia de eucharistia (2003) y Deus caritas (2005), las exhortaciones Christifideles laici (1988) y Ecclesia in America (1999), y la carta Communionis notio (1992). Tampoco aparece en las encíclicas Spe salvi (2007) y Caritas in veritate (2009).

${ }^{51}$ Ver a Galli, "Il ritorno del popolo di Dio. Ecclesiologia argentina e riforma della Chiesa”. 
"muchos rostros" y gran diversidad cultural. Desde este punto de vista, puede decirse que Evangelii gaudium se distancia aquí del Sínodo de 1985, que reinterpretó el Concilio poniendo de relieve justamente un concepto -communio-, pero opacando injustamente otro, "pueblo de Dios".

Quien piensa que el concepto "pueblo" es simplemente intercambiable con el de communio está invitado a leer Evangelii gaudium y, de este modo, a advertir los matices propios que se explicitan con este término deliberadamente escogido por los padres conciliares en el Vaticano II. "La Iglesia es una communio en forma de populus". Por eso, al "vincularse con la categoría de populus, la realidad objetiva de la communio puede ser pensada en relación con su portador (Träger) en la historia de la salvación" 52 .

El oscurecimiento de la noción de pueblo de Dios con su rico contenido conciliar -que continuó luego del Sínodo de 1985- es un testimonio y un símbolo claro del proceso de centralización romana y desvalorización de las iglesias locales, y de la corresponsabilidad de los creyentes en las últimas décadas. No es casualidad que haya perdido consenso precisamente un concepto que pone de manifiesto la dimensión sociohistórica eclesial, que, en analogía con los pueblos históricos, no permite diluir la Iglesia en una realidad interior y atemporal.

El creciente desarrollo de la categoría de "sinodalidad", tanto en la teología en general como en el discurso de Francisco en particular ${ }^{53}$, a diferencia de lo sucedido con el concepto de communio, no se hace en perjuicio de la de "pueblo de Dios", sino de manera complementaria, potenciándose ambas recíprocamente: un caminar juntos, de un sujeto comunitario, histórico, que incluye a todos y todas los creyentes corresponsables en una salida misionera orientada a ofrecer el Evangelio en cada contexto cultural.

La agenda de reforma eclesial en sus diversas instituciones tiene ahora un punto de partida eclesiológico y un punto de vista hermenéutico cualitativamente diferentes, más fieles al Concilio y más aptos para afrontar el desafío de una Iglesia mundial.

\section{Una trasformación metodológica relegada y ahora rehabilitada}

\section{El debate sobre el método en Gaudium et spes}

Son bien conocidos los debates conciliares que existieron en torno al llamado Esquema XIII que, incluso en las semanas decisivas del último periodo de 1965, hicieron

52 Ídem, “El 'retorno' del pueblo de Dios misionero”, 413, 422, 462.

${ }^{53}$ Fernández, Il progetto di Francesco. Dove vuole portare la Chiesa, 80. 
temer por su viabilidad. No existe duda de que una de las principales dificultades se refería al método inductivo ver-juzgar-actuar, introducido en el documento como esquema estructurante en la primavera de 1965.

A pocos meses de finalizado el Concilio, un privilegiado protagonista latinoamericano publicó un interesante artículo que describe el núcleo del problema de entonces. Se trata de Marcos McGrath, quien era obispo auxiliar de la arquidiócesis de Panamá, quien -como presidente de la subcomisión que se ocupaba del tema "signos de los tiempos"- fue el encargado de presentar a la asamblea conciliar, en el último periodo de sesiones, el informe oficial correspondiente a la parte introductoria del texto de la futura constitución. "Hay, en efecto, una peculiaridad que el lector atento debe descubrir si quiere apreciar Gaudium et spes”, advertía McGrath, y calificaba esa "peculiaridad" como "un nuevo método" ${ }_{54}$. Algunas reacciones negativas contra el documento no le llamaban la atención: "Los tradicionalistas miraban la propuesta con recelo y con cierto desdén jocoso. Pensaban seguramente que los asuntos temporales transitorios no eran dignos de un Concilio". Sin embargo, McGrath encontraba extraña la posición de "los así llamados progresistas, que se ocupaban por entonces en pulir brillantemente la nueva visión de la Iglesia en la constitución dogmática Lumen gentium" pero que, en su opinión,

....se rebelaban contra todo lo que pudiera parecer una consideración empírica del mundo. Insistían en que el Concilio debía proceder de acuerdo con el método teológico aceptado, lo que significaba partir de los principios de la revelación, que derivan de las normas de la fe y de la moral, aun para el orden temporal. [...]. Mientras una minoría mostraba un marcado desinterés por el documento, los otros se hallaban profundamente divididos acerca del enfoque que habría que darle. [...]. Esta discusión, confusa y frustradora en ese instante, fue enormemente útil. Por primera vez todos vieron claramente la originalidad del Esquema XIII, como se le llamó entonces por falta de otro título aceptado [signo de la ambigüedad que se mantuvo casi hasta el final]. Había que proyectar un nuevo método para este nuevo tipo de documento. Es este nuevo método, desarrollado y perfeccionado muy lentamente, imperfecto aún en el último borrador de la constitución, el que el lector debe captar si quiere interpretar bien dicha constitución y continuar el diálogo con el mundo que ella ha comenzado.55

Las afirmaciones de McGrath coinciden sustancialmente con la caracterización hecha por Yves Congar: "El Concilio, con el Esquema XIII, pretendía iniciar una forma relativamente nueva de teología, no ya deductiva y abstracta sino inductiva y concreta"s6.

\footnotetext{
${ }^{54}$ McGrath, "La génesis de Gaudium et spes", 495.

${ }^{55}$ Ibid., 496. Cursivas mías.

${ }^{56}$ Congar y otros, La respuesta de los teólogos, 11-18, 14. Cursivas mías.
} 
También G. Routhier estaría de acuerdo con el análisis de McGrath cuando escribió en la famosa Historia dirigida por Alberigo:

No era sencillamente la exactitud de lo que el esquema decía lo que originaba dificultades a los alemanes y a los italianos: ellos cuestionaban el método mismo del esquema. Aunque no se dijo claramente, lo que disgustaba a estos oradores era el método inductivo del esquema, su enfoque empírico y descriptivo. Se hallaban desconcertados porque no hallaban un tratado clásico sobre antropología cristiana. ${ }^{57}$

Este era el "corazón del conflicto", en palabras de C. Theobalds8.

\section{Dos procesos diversos de recepción del método de Gaudium et spes}

En el posconcilio pueden ser claramente diferenciados dos procesos de recepción de Gaudium et spes desde el punto de vista del método: el realizado en América Latina desde la segunda mitad de la década del 60 y el que se concreta en varios autores pertenecientes al ámbito lingüístico alemán.

Como reconocen varios teólogos y teólogas, la metodología de los signos de los tiempos, el esquema hermenéutico ver-juzgar-actuar introducido como idea estructurante en la constitución pastoral, tuvo en el posconcilio un particular desarrollo en América Latina ${ }^{59}$. Esta perspectiva resultó determinante en la manera de abordar la evangelización del continente, particularmente en las conferencias generales del episcopado (Medellín, Puebla, Santo Domingo y Aparecida) y en el surgimiento de la llamada primera teología no europea, la teología de la liberación.

El método cualificó de manera decisiva la forma de pensar la fe y, al promover una mayor conciencia de la propia historia y del propio contexto cultural, colaboró a la configuración de una cierta novedad: la identidad eclesial posconciliar latinoamericana, que encontró en la opción por los pobres su señal más distintiva ${ }^{60}$.

Pueden destacarse dos características del proceso desde el punto de vista del método. Por un lado, hay que reconocer que la metodología del ver-juzgar-obrar tuvo diversas interpretaciones, desde posturas muy simplistas, que comprendían los diversos momentos como pasos sucesivos, a comprensiones más profundas, que advertían

\footnotetext{
${ }^{57}$ Routhier, "Finalizar la obra comenzada: la experiencia del cuarto periodo, una experiencia que ponía a prueba", 143 .

${ }^{58}$ Theobald, Le Concile Vatican II. Quel avenir?, 227, 229.

${ }^{59}$ Ruggieri, "Zeichen der Zeit. Herkunft und Bedeutung einer christlich-hermeneutischen Chiffre der Geschichte ", 67-68.

${ }^{60}$ Ver a Brighenti, "Método ver-julgar-agir".
} 
un círculo hermenéutico de los distintos momentos implicados. Por otro lado, dicho método, que fue admitido sin discusiones en el tiempo de Medellín (1968), sufrió luego continuos embates en las conferencias posteriores, hasta Aparecida (2007), sin excepción, particularmente por parte de las autoridades romanas.

Sin embargo, estas limitaciones y dificultades no restan valor a la evaluación aportada por Víctor Codina: Gaudium et spes ha sido el texto conciliar "que mayor impacto ha tenido en América Latina", precisamente por el aporte de su método, que invita a auscultar y discernir los signos de los tiempos, los signos de la presencia del Espíritu en las aspiraciones y en los deseos profundos de la humanidad ${ }^{61}$.

Este es un método teológico autorizado por el Vaticano II que ha proporcionado una mayor conciencia de la propia historia, que permite valorar más positivamente los procesos culturales en los que la Iglesia está inserta, que capacita para comprender las diferencias y las diversidades en una sociedad plural, que aprecia mejor toda alteridad -cualquiera sea ella- y estimula el surgimiento y el desarrollo de pensamientos y teologías contextuales. En buena medida, el papa Francisco es heredero de esta breve tradición.

Por el contrario, como ha mostrado H.-J. Sander, buena parte de la teología alemana siguió en este punto otro camino ${ }^{62}$, en particular, en relación con la novedad metodológica introducida por Gaudium et spes en la forma de pensar la fe y la teología, las publicaciones de Joseph Ratzinger -ya desde los ańos como perito en el Concilio- oscilan entre una carencia de conciencia significativa del asunto y una actitud prevalentemente negativa. No me refiero aquí a sus críticas más o menos justas a diversos conceptos de la constitución pastoral -pueblo de Dios, mundo, diálogo-, sino a sus opiniones sobre la perspectiva del método, a la "forma de proceder de afuera hacia adentro", como él mismo lo caracterizó entonces ${ }^{63}$.

Es verdad que Ratzinger participó activamente en el debate sobre la revelación, en 1962, que al reafirmar el lugar de la Escritura como alma de la teología tuvo -entre otros aspectos positivos- "un significado casi revolucionario para la forma sistemática de la teología católica", como él mismo escribió en su comentario a Dei Verbum de 196764; pero en otra cuestión clave de la renovación metodológica de la teología por

${ }^{61}$ Codina, "Las iglesias del continente 50 años después del Vaticano II", 84.

${ }^{62}$ Sander, "Theologischer Kommentar zur Pastoralkonstitution über die Kirche in der Welt von heute Gaudium et spes", 838-853; Turbanti, Un Concilio per il mondo moderno. La redazione della costituzione pastorale 'Gaudium et spes' del Vaticano II, 786.

${ }^{63}$ Ratzinger, “Kommentar zum ersten Kapitel des ersten Teil der Pastoralkonstitution über die Kirche in der Welt von heute Gaudium et spes", 802.

64 Ídem, "Einleitung und Kommentar zum Prooemium, zu Kapitel I, II und VI der Offenbarungskonstitution Dei Verbum”, 786-787. 
parte del Concilio, precisamente a la que aluden McGrath, Congar y Codina en las referencias anteriores, el punto de vista de Ratzinger ya fue muy diferente.

Ciertamente que la verificación de la posición personal de este autor tan significativo necesita un trabajo detallado por los matices que incluye ${ }^{65}$. Por una parte, hay fundamentos para mostrar que Ratzinger no se oponía en principio al método del "grupo de teólogos franceses" de entonces, sino más bien a la manera concreta como dicho método se materializó en el borrador de Gaudium et spes en el otoño de $1965^{66}$. Desde esta perspectiva, su posición no representaría una opinión aislada, sino reflejaría una preocupación compartida por padres conciliares y teólogos pertenecientes a distintas corrientes y sensibilidades. Por otra parte, no faltan tomas de posición suyas y claros testimonios de otros actores que atestiguan que él proponía suprimir la primera parte de la constitución y que encontraba un problema de fondo con lo que él llamaba "la forma de proceder de afuera hacia adentro". En su opinión, expresada con múltiples matices, esta forma de proceder comprometía la adecuada comprensión del núcleo del misterio cristiano.

De allí que valorara muy positivamente la formulación cristológica de Gaudium et spes 22: allí se concretaba -en su opinión- "por primera vez en un texto magisterial un nuevo tipo de teología completamente cristocéntrico" que propone a partir de Cristo una "teología como antropología" ${ }^{67}$. El "nuevo tipo de teología" de Ratzinger aquí -más descendente- parece exactamente la cara opuesta de la expresión citada de Congar: "una forma relativamente nueva de teología, no ya deductiva y abstracta sino inductiva y concreta" 68 .

Una lectura atenta de los años posteriores al Concilio en la obra teológica de Ratizinger, de sus trabajos en la Congregación de la Fe, e incluso en sus textos ya como Benedicto XVI permite advertir que, en este punto, no hay ninguna modificación ulterior importante. Esta renovación metodológica de la teología, tan decisiva para el desarrollo de las iglesias de América Latina y para los procesos de inculturación de la fe en los diversos contextos, pasó inadvertida, en el mejor de los casos, en la bibliografía del autor.

\footnotetext{
${ }^{65}$ Ver a Schickendantz, “¿Una transformación metodológica inadvertida? La novedad introducida por Gaudium et spes en los escritos de Joseph Ratzinger”. En este artículo puede verificarse la complejidad del asunto, el cual exije un juicio informado y muy diferenciado.

${ }^{66}$ Ratzinger, "El último periodo de sesiones del Concilio", 491. Ver a Peterson, "Critical Voices: The Reactions of Rahner and Ratzinger to 'Schema XIII' (Gaudium et spes)”, 14.

${ }^{67}$ Ibíd., "Kommentar zum ersten Kapitel”, 857. Cursivas mías. Ver ibíd., 833, 862. Representa, además, lo contrario de lo que Chenu caracterizó como "el alma del esquema”, precisamente una teología que no "deduce de la cristología una antropología cristiana” (Turbanti, Un Concilio per il mondo moderno, 649).

${ }^{68}$ Congar y otros, La respuesta de los teólogos, 14.
} 
Parece razonable considerar que las diferentes perspectivas de Ratzinger, por una parte, y por otra, la que caracteriza la recepción latinoamericana, no se excluyen e incluso que pueden ser vistas como saludables advertencias recíprocas en orden a un equilibrio, es decir, como perspectivas diversas que, bien acogidas, favorecen un enriquecimiento mutuo. No obstante, no se pueden minimizar los presupuestos diversos que encierran y las importantes diferencias que implican para la manera de pensar la fe y la situación del cristianismo en el mundo actual.

Los riesgos - a menudo no evitados- de una mirada prevalentemente negativa a los de "afuera", a toda alteridad - personas, culturas, religiones-, la naturalidad para concretar una "política de la identidad" que se autoafirma frente a lo otro, caracterizado en términos negativos y conflictivos, están a la mano. El curso seguido por la Iglesia en las últimas décadas, en sus decisiones de gobierno y en su enseñanza en variados ámbitos -litúrgico, eclesiológico, ecuménico, etc.- está muy marcado por esta tendencia. La sobrevaloración de la tradición occidental -un renovado eurocentrismoy la acentuación de la centralización romana son síntomas elocuentes.

\section{Reflexión final}

En la introducción se ha descrito el núcleo de una tesis de Karl Rahner que interpreta el acontecimiento del Vaticano II como un "salto cualitativo" en la historia eclesial: "el Concilio Vaticano II ha sido germinalmente la primera autorrealización oficial de la Iglesia en cuanto Iglesia mundial”. Se esboza el inicio de una Iglesia arraigada en las diversas regiones de la tierra que será, cada vez menos, el fruto de una exportación del modelo cultural europeo de cristianismo.

Desde esta perspectiva fundamental he interpretado determinados procesos en tres áreas importantes de la recepción conciliar en estas décadas: ciertos aspectos del ámbito litúrgico caracterizados como la "reforma de la reforma", la recuperación de la categoría de "pueblo de Dios", y la diversa acogida del método teológico que estructura el documento Gaudium et spes, el cual ha impactado de manera considerable, aunque diversa, la vida y la enseñanza de la Iglesia hasta nuestros días. Se advierte en dichas áreas un cambio en el escenario eclesial inaugurado en marzo de 2013, en el sentido en que Rahner auguraba. Por una parte, esta "interpretación fundamental” ayuda a entender el tiempo eclesial en que vivimos y, por otra, dicha tesis parece encontrar su verificación concreta en los hechos que se destacan.

La primera parte ha mostrado que en el pontificado de Benedicto XVI estaba en realización un desarrollo muy definido en el campo litúrgico que ha encontrado, al menos, un freno en el gobierno de Francisco. Advertimos allí, particularmente, dos límites: (1) Una cuestionable interpretación de Sacrosanctum Concilium, y con ella, del mismo del 
Concilio; (2) un proceso de "reforma de la reforma" litúrgica -verificado en varias decisiones concretas- guiado más por la preocupación de una traducción literal que por un renovado esfuerzo creativo de inculturación. Los matices son importantes y necesitan una reflexión detallada. Aquí solo podían ofrecerse algunos argumentos más relevantes.

En segundo lugar, se puso de relieve, con el testimonio de múltiples autores destacados, el recorrido que ha tenido en el posconcilio la categoría central de la eclesiología del Vaticano II: pueblo de Dios. Que el oscurecimiento del concepto se haya producido en el mismo momento en que se demandaba una hermenéutica menos unilateral y más respetuosa del texto, no solo del espíritu conciliar, es digno de advertir. He procurado mostrar brevemente que la pérdida de la noción de "pueblo de Dios" tiene efectos colaterales importantes por la riqueza teológica que representa. Los padres conciliares hicieron una elección consciente y fundada al privilegiar esa categoría. El paso adelante concretado en el magisterio de Francisco es, a la vez más, más fiel al texto conciliar y, por la riqueza de la categoría y la teología que lo sustenta, más apto para afrontar el proceso de inculturación de la Iglesia en los diversos espacios humanos y regionales de nuestro mundo.

En tercer lugar, con la ayuda de un protagonista autorizado, el texto muestra un punto central del debate conciliar en torno al método teológico de Gaudium et spes, que siguió diferentes recorridos en distintas regiones. Bajo la forma del método ver-juzgar-actuar tuvo una enorme repercusión teológica y pastoral en América Latina $^{69}$. Por el contrario, la recepción en múltiples autores alemanes, ya desde la época del Concilio, particularmente la de J. Ratzinger-Benedicto, mostró muchas reservas con esta forma de proceder $^{70}$.

Es verdad que estas afirmaciones generales necesitan muchos matices para ser justamente comprendidas. En esta contribución solo se han ofrecido algunos testimonios destacados ${ }^{71}$. Cierto es que un método teológico-pastoral que presta más atención al momento inductivo ofrece un instrumento valioso para comprender las situaciones concretas, en síntesis, para procesos de inculturación y de mayor respeto por las diferencias contextuales. Se observa en este punto un "salto cualitativo" entre Ratzinger-Benedicto y la experiencia eclesial que aporta Francisco.

\footnotetext{
${ }^{69}$ Ver a Brighenti, "Método ver-julgar-agir".

${ }^{70}$ Sander, "Theologischer Kommentar zur Pastoralkonstitution über die Kirche in der Welt von heute Gaudium et spes”, 838-853.

${ }^{71}$ Un análisis más detallado puede verse en Schickendantz, “¿Una transformación metodológica inadvertida?".
} 
A la luz de este camino recorrido podemos preguntarnos: ¿Ha llegado con Francisco -un típico "producto" posconciliar latinoamericano-, incluso en parte inadvertidamente (porque ahora no hay intención explícita de interpretación del Concilio), el tiempo de la Iglesia como pueblo de Dios, el momento propicio de Gaudium et spes desde la perspectiva del método?

Una particular periferia eclesial ha llevado al centro una diversa sensibilidad litúrgica y experiencia cultural, una "renovada" perspectiva eclesiológica, una "nueva" manera de pensar la fe, "una forma relativamente nueva de teología" (Congar), que revela y perfila, también, un determinado tipo de identidad cristiana en el mundo actual. Que el modelo de reforma sinodal con su "saludable descentralización" (Evangelii gaudium 16), por una parte, y el anhelo de justicia y el sufrimiento de los seres humanos de hoy, por otra, estén ahora-más que antes- en el centro de la agenda eclesial, no es futo del azar.

En orden a perfilar un determinado tipo de eclesiología, para el Vaticano II no era indiferente la conceptualización que se asumiera. Para percibir y solidarizarse más profundamente con "los gozos y las esperanzas, las tristezas y las angustias de los seres humanos de nuestro tiempo, sobre todo de los pobres y de cuantos sufren" (Gaudium et spes 1), el método escogido por los padres conciliares no era insignificante, como lo recuerda la cita de McGrath.

El amplio consenso eclesial e internacional que a todas luces cosecha este tipo de identidad tampoco es una casualidad. Es un efecto benéfico de la germinal perspectiva intercultural del Vaticano II, de la recuperación de la eclesiología conciliar del pueblo de Dios, con su "lógica igualitaria", de la asunción más profunda de la forma de proceder de Gaudium et spes, que tiene tantas repercusiones en los más diversos ámbitos teológicos y pastorales.

En los términos de la "interpretación fundamental” de Rahner presentada al inicio es posible formular está hipótesis: ¿Es Ratzinger-Benedicto el último papa perteneciente a la segunda época en la historia de la Iglesia caracterizado por el modelo exportador de un tipo cultural y teológico de cristianismo? ¿Es Francisco el primer papa del inicio del tercer periodo del cristianismo, el del tránsito de "una Iglesia occidental a una Iglesia mundial”? ¿Está en proceso de realización práctica el "salto cualitativo” formulado teóricamente en el Vaticano II como inicio de una Iglesia mundial? 


\section{Bibliografía}

Baldisseri, Lorenzo. Il Sinodo dei Vescovi al servizio di una Chiesa sinodale. A cinquant'anni dall'Apostolica solicitude. Roma: Librería Editrice Vaticana, 2016.

Baldovin, John. Reforming the Liturgy. A Response to the Critics. Collegeville (MN): Liturgical Press, 2008.

Benedetto XVI. Ultime conversazioni. Editado por P. Seewald. Milano: Garzanti, 2016.

Bogaz, Antonio, y Joao Henrique Hansen. "Sacrosanctum Concilium”. En Dicionário do Concílio Vaticano II, editado por J. Decio Passos y W. Lopes Sanchez, 860-867. São Paulo: Paulinas, 2015.

Brighenti, Agenor. "Método ver-julgar-agir". En Dicionário do Concílio Vaticano II, editado por J. Decio Passos y W. Lopes Sanchez, 608-615. São Paulo: Paulinas, 2015 .

Codina, Víctor. "Las iglesias del continente 50 años después del Vaticano II". En 50 años del Vaticano II, editado por Congreso Continental de Teología, 81-92. Bogotá: Paulinas, 2013.

Congar, Yves y otros. La respuesta de los teólogos. Buenos Aires: Carlos Lohlé, 1970.

Diekmann, Godfrey. "Estados Unidos y Canadá”. Concilium 12 (1966): 301-309.

Díez Valladares, Lino. "El desafío litúrgico del papa Francisco". Phase 319 (2014): 94-99.

Faggioli, Massimo. La onda larga del Vaticano II. Por un nuevo posconcilio. Santiago de Chile: Editorial Universidad Alberto Hurtado, 2017. . True Reform. Liturgy and Ecclesiology in Sacrosanctum Concilium. Collegeville (MN): Liturgical Press, 2012.

. Vatican II. The Battle for Meaning. Mahwah (NJ): Paulist Press, 2012.

Fernández, Victor Manuel. Il progetto di Francesco. Dove vuole portare la Chiesa. Bologna: EMI, 2014.

Galli, Carlos María. “El ‘retorno’ del pueblo de Dios misionero. Un concepto-símbolo de la eclesiología del Concilio a Francisco". En La eclesiología del Concilio Vaticano II, editado por V. Azcuy, C. Caamańo y C. M. Galli, 405-471. Buenos Aires: Ágape, 2015.

. "Il ritorno del popolo di Dio. Ecclesiologia argentina e riforma della Chiesa". Il Regno 5 (2015): 294-300. 
Gerhards, Albert. "Die Sorge der Päpste. Das Motu proprio Benedikts XVI. Zur Wiederzulassung der alten Liturgie". Herder-Korrespondenz 61 (2007): 398-403.

Girardi. Luigi, y Andrea Grillo. "Sacrosanctum concilium. Introduzione”. En Commentario ai documenti del Vaticano II, Vol. I. Sacrosanctum Concilium. Inter mirifica, editado por S. Noceti y R. Repole, 13-80. Bologna: EDB, 2014.

Giraudo, Cesare. "La riforma liturgica a 50 anni dal Vaticano II. 'Parlare di riforma della riforma’ è un errore”. La civiltà cattolica 3995 (2016): 432-445.

Kaczynski, Reiner. "Hacia la reforma litúrgica". En Historia del Concilio Vaticano II. Vol. III. El concilio adulto, dirigido por G. Alberigo, 173-227. Salamanca: Sígueme, 2006.

Koch, Kurt. "Pope's 'Reform of the Reform' in Liturgy to continue" (2011). http:// www.catholicherald.co.uk/news/2011/05/16/popes-reform-of-the-reform-inliturgy-to-continue (consultado el 15 de diciembre de 2016).

Komonchak, Joseph. "El debate teológico". Concilium 208 (1986): 381-392.

Marini, Piero. A Challenging Reform. Realizing the Vision of the Liturgical Renewal. Collegeville (MN): Liturgical Press, 2007.

McGrath, Marcos. "La génesis de Gaudium et spes". Mensaje 153 (1966): 495-502.

McManus, Frederick. "El poder jurídico del obispo en la constitución sobre la sagrada liturgia”. Concilium 2 (1965): 32-50.

Orobator, Agbonkhianmeghe. "After all, Africa is Largely a Nonliterate Continent'. The Reception of Vatican II in Africa". Theological Studies 74 (2013): 284-301.

Pablo VI. "Concistoro per la nomina di venti cardinali (1976)". Vatican, http:// w2.vatican.va/content/paul-vi/it/speeches/1976/documents/hf_p-vi_ spe_19760524_concistoro.html (consultado el 15 de diciembre de 2016).

. “Omelia, I Domenica di Quaresima (1965)”. Vatican, http://w2.vatican.va/ content/paul-vi/it/homilies/1965/documents/hf_p-vi_hom_19650307.html (consultado el 15 de diciembre de 2016).

. “Udienza generale (1965)". Vatican, http://w2.vatican.va/content/paul-vi/it/ audiences/1965/documents/hf_p-vi_aud_19650728.html (consultado el 15 de diciembre de 2016).

Peterson, Brandon. "Critical Voices: The Reactions of Rahner and Ratzinger to 'Schema XIII' (Gaudium et spes)”. Modern Theology 31 (2015): 1-26. 
Polanco, Rodrigo. "Concepto teológico de recepción con vistas a su aplicación al desarrollo posterior al Concilio Vaticano I". Teología y vida 54, N. 2 (2013): 205-231.

Pottmeyer, Hermann. "La Chiesa in cammino, per configurarsi come popolo di Dio". En La riforma e le riforme nella Chiesa, editado por A. Spadaro y C. M. Galli, 66-81. Brescia: Queriniana, 2016.

Rahner, Karl. Cambio estructural de la Iglesia. Madrid: Cristiandad, 1974.

. "Theologische Grundinterpretation des II. Vatikanischen Konzils". En Schriften zur Theologie. Band 14, editado por K. Rahner, 287-302. Einsidedeln: Benzinger Verlag, 1980.

Ratzinger, Joseph. "Conferencia del cardenal J. Ratzinger sobre la eclesiología de la Lumen gentium (2000)". Vatican, http://www.vatican.va/roman_curia/ congregations/cfaith/documents/rc_con_cfaith_doc_20000227_ratzinger-lumen-gentium_sp.html (consultado el 10 de diciembre de 2016).

."Einleitung und Kommentar zum Prooemium, zu Kapitel I, II und VI der Offenbarungskonstitution Dei Verbum”. En Gesammelte Schriften. Band 7/2. Zur Lehre des Zweiten Vatikanischen Konzils. Band 7/2, editado por J. Ratzinger, 715-791. Freiburg: Herder, 2012.

. "El último periodo de sesiones del Concilio". En Obras completas VII/1. Sobre la enseñanza del Concilio Vaticano II, editado por J. Ratzinger, 474-523. Madrid: Biblioteca de Autores Cristianos, 2013.

."Kommentar zum ersten Kapitel des ersten Teil der Pastoralkonstitution über die Kirche in der Welt von heute Gaudium et spes”. En Gesammelte Schriften. Band 7/2. Zur Lehre des Zweiten Vatikanischen Konzils. Band 7/2, editado por J. Ratzinger, 795-861. Freiburg: Herder, 2012. . Mi vida. Recuerdos (1927-1977). Madrid: Encuentro, 1997.

. Obras completas. Vol. XI. Teología de la liturgia. Madrid: Biblioteca de Autores Cristianos, 2012.

. "Prefazione”. En K. Gamber, La réforme liturgique en question, Le Barroux 1992. www.messainlatino.it/pag11_sito.htm (consultado el 10 de diciembre de 2016).

Ratzinger, Joseph, y Vitorio Messori. Informe sobre la fe. Madrid: Biblioteca de Autores Cristianos, 1985. 
Rau, Enrique. "La reforma litúrgica en Latino-América”. Concilium 12 (1966): 298-300.

Routhier, Gilles. "Finalizar la obra comenzada: la experiencia del cuarto periodo, una experiencia que ponía a prueba”. En Historia del Concilio Vaticano II, Vol V, dirigido por G. Alberigo, 59-177. Salamanca: Sígueme, 2008.

Ruggieri, Giuseppe. "Zeichen der Zeit. Herkunft und Bedeutung einer christlichhermeneutischen Chiffre der Geschichte". En Das Zweite Vatikanische Konzil und die Zeichen der Zeit heute, editado por P. Hünermann, 61-70. Freiburg i.Br.: Herder, 2006.

Russo, Roberto. "Sacrosancum Concilium e riforma liturgica in America Latina: vita liturgica e questione popolare”. En Il Concilio Vaticano II e la liturgia: memoria e futuro, editado por P. Chiaramello, 219-246. Roma: Ed. Liturgiche, 2013.

Sala Stampa della Santa Sede. "Comunicado de la oficina de prensa de la Santa Sede. (2016)". Oficina de Prensa. Vaticano, http://press.vatican.va/content/salastampa/ it/bollettino/pubblico/2016/07/11/0515/01177.html\#es (consultado el $20 \mathrm{de}$ diciembre de 2016).

Sander, Hans-Joachim. "Theologischer Kommentar zur Pastoralkonstitution über die Kirche in der Welt von heute Gaudium et spes". En Herders Theologischer Kommentar zum Zweiten Vatikanischen Konzil. Band 4, editado por P. Hünermann y B.-J. Hilberath, 581-886. Freiburg i.Br.: Herder, 2005.

Sarah, Robert. "Towards an Authentic Implementation of Sacrosanctum Concilium (2016)". Google Drive, https://drive.google.com/file/d/0B8CZzED2HiWJNzdaOE9ycVI4ekU/view (consultado el 10 de diciembre de 2016).

Scardilli, Pietro Damiano. I nuclei ecclesiologici nella costituzione liturgica del Vaticano II. Roma: Editrice Pontificia Università Gregoriana, 2007.

Schickendantz, Carlos. "La reforma de la Iglesia en clave sinodal. Una agenda compleja y articulada”. Teología y vida 58, N. 1 (2017): 35-60.

- "La reforma de la reforma litúrgica. Un diagnóstico con poco consenso del obispo emérito de Roma”. Mensaje 617 (2013): 40-43.

. "¿Una transformación metodológica inadvertida? La novedad introducida por Gaudium et spes en los escritos de Joseph Ratzinger". Teología y vida 57, No. 1 (2016): 9-37.

Spadaro, Antonio; y Carlos María Galli (eds.), La riforma e le riforme nella Chiesa. Brescia: Queriniana, 2016. 
Theobald, Christoph. Le Concile Vatican II. Quel avenir? Paris: Cerf, 2015.

Tillard, Jean Marie. "El 'Informe final' del último Sínodo”. Concilium 208 (1986): 393-407.

Turbanti, Giovanni. Un Concilio per il mondo moderno. La redazione della costituzione pastorale 'Gaudium et spes' del Vaticano II. Bologna: Il Mulino, 2000.

Vitali, Dario. "I soggetti della sinodalità alla luce dell'ecclesiologia del Concilio Vaticano II". En A cinquant'anni dall'Apostolica solicitudo. Il Sinodo del vescovi al servicio di una Chiesa sinodale, editado por L. Baldisseri, 141-189. Città del Vaticano: Libreria Editrice Vaticana, 2016.

. Popolo di Dio. Assisi: Cittadella Editrice, 2013.

Wirz, Matthias (ed.). Riformare insieme la Chiesa. Magnano: Edizioni Qiqajon, 2016. 